\title{
Situs Inversus Totalis: A Rare Congenital Anomaly and the Presence of COPD Giving a Concept of Dextroposition with Limb Lead Reversal in ECG
}

\author{
Khandker Md. Nurus Sabah¹, Abdul Wadud Chowdhury², Mohammad Shahidul Islam³, Mohammad Gaffar Amin ${ }^{1}$, \\ Md. Azizul Hassan Khandakar ${ }^{4}$, Shamima Kawser ${ }^{5}$
}

\begin{abstract}
:
Situs inversus totalis is the mirror-image of normal position of the thoracic and abdominal viscera. It may be detected incidentally when the patient seek medical attention for other medical illness. From medico-legal points of view, this rare disorder is important in many ways for a junior physician to prevent a big mishap,
\end{abstract}

especially surgical. Here, we report a case, who was 55year-old, seeking medical attention for infective exacerbation of chronic obstructive pulmonary disease incidentally diagnosed as a case of situs inversus totalis. Key words: Situs inversus, Dextrocardia, ECG.

(Bangladesh Heart Journal 2016; 31(2) : 100-103)

\section{Introduction:}

Situs inversus totalis, also familiar as dextrocardia with situs inversus, situs transverses or opposites is a congenital condition in which the visceral organs of chest and abdomen are reversed from their normal position, giving a mirror-image of normal. It is first described by Matthew Ballie in $1788^{1}$. For normal cardiovascular and abdomninal visceral functioning, it may not be detected in whole life, may be detected incidentally when they seek medical attention for an unrelated condition, in postmortem or while dissection of cadaver in anatomy dissection teaching class. Last year, a 55-year-old farmer came to us with the infective exacerbation of chronic obstructive pulmonary disease. Incidentally, situs inversus totalis was identified.

1. Assistant Professor, Department of Cardiology, Dhaka Medical College, Dhaka, Bangladesh.

2. Professor \& Head of Department, Department of Cardiology, Dhaka Medical College, Dhaka, Bangladesh.

3. Registrar, Department of Medicine, Anwer Khan Modern Medical College, Dhaka, Bangladesh.

4. Junior Consultant, Adomdighi Health Complex, Bogra, Bangladesh.

5. Associate Professor, Dr. Sirajul Islam Medical College, Dhaka, Bangladesh.

Address of Correspondence: Dr. Khandker Md. Nurus Sabah, Assistant Professor, Department of Cardiology, Dhaka Medical College Hospital, Dhaka, Bangladesh. E-mail: sabahkmn09@gmail.com

\section{Case Presentation:}

A 55-year-old Bangladeshi, chain-smoker, farmer presented with high-grade fever, breathlessness for 1 week. He gave history of dry cough and mild short of breath for last 2 years. Now he had fever, that came without chills and rigor, maximum temperature $103^{\circ} \mathrm{F}$, persisted most of the time of day and it subsided after taking antipyretic drugs. Initially he had mild short of breath. Later it progressed day by day. On admission, patient was toxic, having respiratory distress with respiratory rate 34 breaths/min with wheeze heard with unaided ear, blood pressure $-140 / 90 \mathrm{~mm} \mathrm{Hg}$, pulse -140 beats/ min and regular, nicotine staining in nails of hands. There was no clubbed finger, cyanosis, Examination of chest revealed features of chronic obstructive pulmonary disease. Examination of precordium revealed apex beat not felt, heart sound was very distant, more prominent on right side of sternum. Clinical presentation and examination findings were suggestive of infective exacerbation of chronic obstructive lung disease.

Complete blood count revealed high WBC count with neutrophilic leucocytosis. ESR was $40 \mathrm{~mm}$ in $1^{\text {st }}$ hour. There were normal electrolytes and slightly raised serum creatinine $(1.49 \mathrm{mg} / \mathrm{dl})$.

Electrocardiography showed heart rate 140 per minute with sinus rhythm, right axis deviation, prominently 


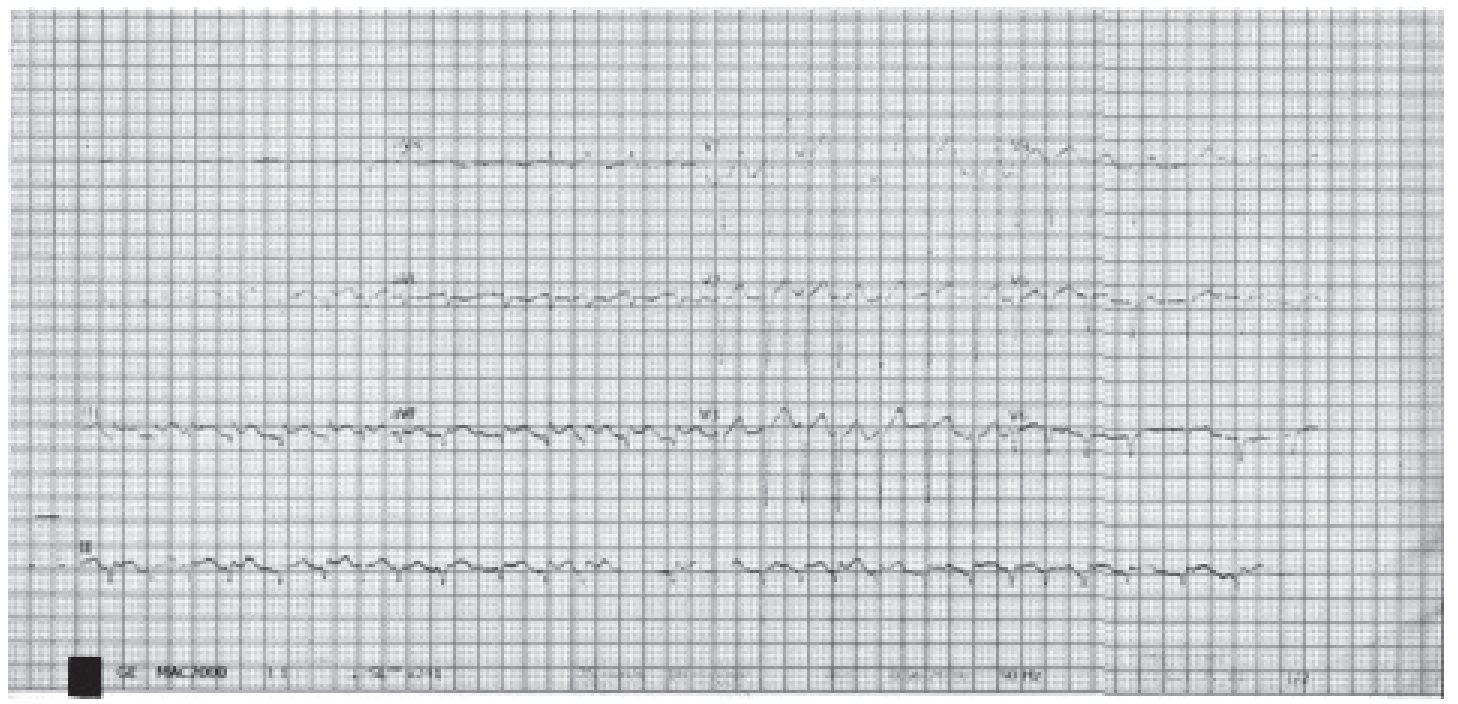

Fig.-I: Electrocardiography of a patient with dextrocardia with situs inversus

negative $\mathrm{P}$ wave, QRS complexes and $\mathrm{T}$ wave in lead I, normal $P$ wave in inferior leads, flattened $P$ wave in avL, positive QRS complexes with upright $P$ and flattened $T$ wave in avR, absence of $R$ wave and prominent of $S$ wave in chest leads (Figure I). Initially it was thought to be due to erroneous positional change of limb leads. After checking the position of limb leads, it was taken and revealed the same findings. Later chest radiography revealed dextrocardia with the cardiac apex pointing to the right side, the aortic arch and stomach bubble located on the right and features of chronic obstructive pulmonary disease with hyperinflated lung shadow, low flat diaphragm, widening of intercostals space and horizontal ribs. Colour Doppler Echocardiography mentioned situs inversus with dextrocardia with L- loop ventricle and Lnormal great vessels, normal size cardiac chambers and normal ejection fraction.

USG of whole abdomen revealed mirror-image anatomy of the abdominal viscera with liver on left side and spleen on right side and no other abnormality. Radiography of paranasal sinus revealed no abnormality. All the findings were suggestive of situs inversus totalis. For COPD, he was treated according to the hospital protocol and discharged on $7^{\text {th }}$ day of hospitalization after clinical improvement.

It showed heart rate 140 per minute with sinus rhythm, right axis deviation, prominently negative $P$ wave, QRS complexes and $T$ wave in lead I, normal $P$ wave in inferior leads, flattened $\mathrm{P}$ wave in avL, positive $\mathrm{QRS}$ complexes with upright $P$ and flattened $T$ wave in avR, absence of $R$ wave and prominent of $S$ wave in chest leads (though it is not a good quality of electrocardiography)

\section{Discussion:}

Situs inversus totalis is a rare congenital anomaly, occurs approximately 2 in 10,000 births ${ }^{2}$. Unfortunately, there is no registry in Bangladesh. Only few cases were reported $3,4,5,6$.

This positional anomaly is important for a physician as 1) to prevent a surgical disaster in diagnosis and/ or surgical intervention following failure to identify the reversed anatomy or an atypical history as cholecystitis causes left upper quadrant pain 2) for the prevention of false- negative reporting by the radiologist resulting from inattention to labelling or false-labelling by a technician 3 ) to avoid misleading electrocardiographic findings 4) to evaluate all cardiac structure in an organized way as a small proportion have some form of congenital heart disease 5) to identify another disease 'kartagener syndrome' having bronchiectasis, sinusitis and situs invertus.

This disease is transmitted usually but not invariably in an autosomal recessive manner. It is found in X-linked pattern of inheritence and in identical twins 7,8 . Abnormalities in Lefty gene, nodal gene, ZIC 3, ACVR2B and Pitxz gene is identified but not obvious culprit for this left-right asymmetry 9,10 . Still research is going on. Some predisposing factors- materanal diabetes, family history of malformations, cocaine use during the 2 months before conception and through the first trimester or being a conjoined twin may increase the risk of heterotaxy mentioned in the review of the data from the BaltimoreWashington Infant Study 11, 12. 
Many people with situs inversus totalis are unaware of their visceral positional abnormality in whole life as they are phenotypically unimpaired and lead normal healthy life that was seen in this case though it depends on associated congenital defects and the presence of cardiovascular compromise. Congenital heart disease is observed in only $3 \%$ cases of situs inversus totalis. Of these patients, $80 \%$ have a right-sided aortic arch ${ }^{2}$. In $20 \%$ cases, kartagener syndrome is seen; however, only $50 \%$ of patients with kartagener syndrome have situs inversus 2, 13. Here, It is better to mention that in dextrocardia, the arrangements of the position of the abdominal viscera may be normal (situs solitus), reversed (situs inversus) and indeterminate (situs ambiguous) in $34.4 \%, 39.2 \%$ and $26.4 \%$ cases respectively ${ }^{14}$.

It may be recognized first by using radiography or ultrasonography. Computed tomography scanning is the preferred examination for the details of visceral organ position, cardiac apical position and great vessels branching and the degree of confidence is high. In this case, ultrasonography had being preferred option and further no question aroused.

Sometimes, electrocardiography gives a clue to a diagnosis of dextrocardia. It shows inverted P, QRS and $T$ wave in lead I \& aVL, positive deflection in aVR with decreasing amplitude of $R$ wave from lead $V_{1}$ through $V_{6}$. A same feature is seen in case of reversal of the arm leads except decreasing $R$ wave amplitude in $V_{1}-V_{6}$. When chronic obstructive lung disease is present, right axis deviation, poor $R$ wave progression is seen in $V_{1}$ through $\mathrm{V}_{6}{ }^{15,16}$. In this case, after getting ECG report, it was thought to be a case of COPD with reversal of limb leads. Later, this concept proved to be a wrong one when repeat ECG with correcting limb lead position, chest radiography and echocardiography was done.

Many of the junior physicians can miss this easily if he or she doesn't look this carefully. This case report emphasizes to know this rare anomaly when dextrocardia is present with situs inversus.

\section{Conclusions:}

It is high-lighted to know this and keep in mind of a physician for correct diagnosis and for the prevention of surgical mishap. If there is any doubt after getting electrocardiography or radiological reports, it is best to examine again bedside and consult with concerning specialist, even with technician or repeat the test.

\section{Acknowledgement}

We acknowledge all the clinical staff of Department of Cardiology, Dhaka Medical College Hospital for cordial co-operation in this case.

\section{References:}

1. Baillie M. An Account of a Remarkable Transposition of the Viscera. By Matthew Baillie, MD In a Letter to John Hunter, Esq. FRS. Philosophical Transactions of the Royal Society of London. 1788 Jan 1;78: 350-63.

2. Brown DW, Fulton DR. Congenital Heart Disease in Children and Adolescents. In Fuster V, Walsh RA, Harrington RA, editors. Hurst's The Heart. 13th ed. New Delhi: The McGraw-Hill Companies, Inc.; 2011. p. 1827-83

3. Ahmed JU, Hossain GZ, Karim MM, Hossain AI, Ahmed M, Bhuya MS. Left sided acute appendicitis with situs inversus in an elderly-an unusual case. Journal of Chittagong Medical College Teachers' Association. 2007;18(1):29-31.

4. Rahman ML, Chowdhury MM, Kalam SM. Off-Pump Total Myocardial Revascularization for Dextrocardia and Situs Inversus. KYAMC Journal. 2013 Jan $15 ; 1(2): 83-4$

5. Ahsan SA, Rahman H, Hossain AS, Siddique MA, Mahmood M. Successful Percutaneous Coronary Interventionin a Patient with Dextrocardia and Situs Inversus-a case report. University Heart Journal. 2013 Aug 5;8(2):137-9.

6. Sheikh N, Banerjee SK, Hossain MZ, Islam MT, Karim T, Hasan Al, Adhikary DK, Hasan MN, Hoque $\mathrm{MH}$. Subpulmonary Obstruction Due to Aneurysmal Ventricular Septum in a Patient with Congenitally Corrected Transposition of the Great Arteries and Dextrocardia. University Heart Journal. 2015 Aug 20;10(1):31-8.

7. Casey B, Devoto M, Jones KL, Ballabio A. Mapping a gene for familial situs abnormalities to human chromosome Xq24-q27. 1. Nature genetics. 1993 Dec 1;5(4):403-7.

8. Levin M, Roberts DJ, Holmes LB, Tabin C. Laterality defects in conjoined twins. Nature. 1996 Nov 28;384(6607):321.

9. Casey B. Two rights make a wrong: human leftright malformations. Human Molecular Genetics. 1998 Sep 1;7(10):1565-71. 
10. Jia JK, Xue HZ, Shen Q. One case of transposition of viscera and hepatic and extrahepatic bile duct stones. Life Science Journal. 2013;10(3): 1522-3.

11. Ferencz C, Rubin JD, Loffredo CA, Megee CA, eds. Epidemiology of congenital heart disease: the Baltimore-Washington Infant Study 1981-1989. $1^{\text {st }}$ ed. Mount Kisco, NY: Futura Publishing Company; 1993 Jan.

12. Alverson CJ, Strickland MJ, Gilboa SM, Correa A. Maternal smoking and congenital heart defects in the Baltimore-Washington Infant Study. Pediatrics. 2011 Feb 22:peds-2010.

13. Rooklin AR, McGeady SJ, Mikaelian DO, Soriano RZ, Mansmann HC. The immotile cilia syndrome: a cause of recurrent pulmonary disease in children. Pediatrics. 1980 Oct 1;66(4):526-31.

14. Garg N, Agarwaal BL, Modi N, Radhakrishnan S, Sinha N. Dextrocardia: an analysis of cardiac structures in 125 patients. International journal of cardiology. 2003 Apr 30;88(2):143-55.

15. Khan GM editor. Miscellaneous Conditions Dextrocardia: True Dextrocardia (with Sinus Inversus). In Rapid ECG Interpretation. New Jersey: Human Press Inc; 2008. p. 234-6.

16. O'Keefe JH, Hammill SC, Freed MS, Pogwizd SM, editors. ECG Criteria. In The Complete Guide to ECGs. 3rd ed. USA: Jones and Bartlett Publishers; 2008. p. $549-50$. 